\title{
Increased production of interleukin $1 \beta$ and hepatocyte growth factor may contribute to foveolar hyperplasia in enlarged fold gastritis
}

Y Yasunaga, Y Shinomura, S Kanayama, Y Higashimoto, M Yabu, Y Miyazaki, S Kondo, Y Murayama, H Nishibayashi, S Kitamura, Y Matsuzawa

\begin{abstract}
Background and Aims-It has been reported that eradication of Helicobacter pylori improves fold width in $H$ pylori associated enlarged fold gastritis. The aim of this study was to clarify the mechanism of fold thickening in this condition.

Patients and Methods-In eight patients with enlarged fold gastritis and 13 patients without enlarged folds, the presence of $H$ pylori infection, inflammatory infiltrates, mucosal plasia, and epithelial cell proliferation in the body mucosa were investigated, and production of transforming growth factor $\alpha$ (TGF $\alpha$ ), hepatocyte growth factor (HGF), and interleukin $1 \beta$ (IL 1ß) was determined by a competitive reverse transcription/polymerase chain reaction method and in vitro short-term culture of biopsy specimens.
\end{abstract}

Results-In the patients with enlarged fold gastritis, inflammatory infiltrates including macrophages increased with $H$ pylori colonisation in the body. Foveolar thickness and proliferating cell nuclear antigen (PCNA) labelling index were increased. Messenger RNA levels of HGF, but not TGF $\alpha$, were increased, and release of HGF and IL $1 \beta$ was increased. HGF release, which was positively correlated with IL $1 \beta$ release and foveolar thickness, decreased in the presence of IL 1 receptor antagonist. After eradication of $H$ pylori, inflammatory infiltrates, IL $1 \beta$ and HGF release decreased with concomitant decreases in PCNA labelling index, foveolar thickness and fold width.

Conclusions-Increased IL $1 \beta$ and HGF production caused by $H$ pylori infection may contribute to fold thickening of the stomach by stimulating epithelial cell proliferation and foveolar hyperplasia in patients with enlarged fold gastritis.

(Gut 1996; 39: 787-794)

Keywords: Helicobacter pylori, enlarged fold gastritis, interleukin $1 \beta$, hepatocyte growth factor, foveolar hyperplasia.

Enlarged folds in the gastric body are not an uncommon finding on radiographic or endoscopic examinations in adults. They are typically associated with a variety of diseases including hypertrophic gastritis, Ménétrier's disease, Zollinger-Ellison syndrome, primary gastrin cell hyperplasia, carcinoma, and lymphoma. ${ }^{2}$ As a special form of gastritis accompanied by mucosal hyperplasia of the stomach has been reported, ${ }^{3}$ inflammation of the gastric mucosa is thought to affect proliferation and differentiation of gastric epithelial cells. However, the mechanism by which inflammation of the gastric mucosa causes mucosal hyperplasia of the stomach is unknown.

Transforming growth factor $\alpha(\mathrm{TGF} \alpha)$ and hepatocyte growth factor (HGF) are well known potent stimulators of gastric epithelial cell proliferation. ${ }^{4} \mathrm{TGF} \alpha$, which is produced by gastric epithelial cells, was reportedly overexpressed in the gastric mucosa of a patient with Ménétrier's disease. ${ }^{6}$ It also has been reported that TGF $\alpha$ transgenic mice showed a number of features characteristic of Ménétrier's disease. ${ }^{7}$ Recently, HGF, which was originally identified as a growth factor for hepatocytes, has been shown to have the potential to stimulate growth of gastric epithelial cells. ${ }^{58} \mathrm{HGF}$ production has been demonstrated by non-epithelial cells such as mesenchymal cells and granulocytes. ${ }^{8-11}$ Reportedly, HGF may be induced by interleukin $1 \beta$ (IL $1 \beta$ ), a cytokine that plays a key part in the inflammatory and immunological responses. ${ }^{12-14}$

Recently, Helicobacter pylori has been well known as a cause of chronic active gastritis, ${ }^{15}$ and it has been suggested that $H$ pylori gastritis may be one of the causes of enlarged gastric folds. ${ }^{16}{ }^{17}$ We have previously reported that eradication of $H$ pylori improves inflammation of the gastric mucosa and fold width in $\mathrm{H}$ pylori positive patients with enlarged folds; these findings suggest that $H$ pylori infection may cause gastritis accompanied with enlarged folds - that is, 'enlarged fold gastritis'. ${ }^{18}$ In agreement with our findings, improvement in fold thickening after eradication of $H$ pylori has been reported by Stolte $e t a l^{19}{ }^{20}$ and Avunduk et $a l .{ }^{21}$ To clarify the mechanism of thickening of the gastric folds in patients with enlarged fold gastritis, we investigated TGF $\alpha, \mathrm{HGF}$ and IL $1 \beta$ production in the gastric body mucosa as well as the presence of $H$ pylori infection, inflammatory infiltrates, mucosal plasia, and epithelial cell proliferation in patients with enlarged fold gastritis. 
TABLE I H pylori infection, sex, age, and fold width

\begin{tabular}{|c|c|c|c|}
\hline & $\begin{array}{l}\text { Sex } \\
\text { (male/female) }\end{array}$ & $\begin{array}{l}\text { Age } \\
(y)\end{array}$ & $\begin{array}{l}\text { Fold width } \\
(\mathrm{mm})\end{array}$ \\
\hline $\begin{array}{l}\text { Enlarged fold gastritis* }(n=8) \\
H \text { pylori }(+)(n=8) \\
\text { Non-enlarged fold }(n=13)\end{array}$ & $5 / 3$ & $42 \cdot 5(4 \cdot 4),(30-68)$ & $10 \cdot 6(0 \cdot 6),(7-12)$ \\
\hline $\begin{array}{l}\text { H pylori }(+)(\mathrm{n}=5) \\
\text { H pylori }(-)(\mathrm{n}=8)\end{array}$ & $\begin{array}{l}4 / 1 \\
4 / 4\end{array}$ & $\begin{array}{l}43 \cdot 8(2 \cdot 1),(39-50) \\
47 \cdot 8(2 \cdot 9),(39-62)\end{array}$ & $\begin{array}{l}4 \cdot 4(0 \cdot 3),(4-5) \dagger \\
2 \cdot 6(0 \cdot 2),(2-3)\end{array}$ \\
\hline
\end{tabular}

Age and fold width are expressed as mean (SEM), (range). ${ }^{\star}$ Enlarged fold gastritis, gastritis accompanied with enlarged folds (the widest fold $>5 \mathrm{~mm}$ ). $+\mathrm{p}<0.01 v$ non-enlarged fold, $H$ pylori (-). 3,3'-diaminobenzidine tetrachloride as a substrate. Negative control was used with mouse IgG (Dako) instead of the anti-CD68, and no detectable staining was seen. Lymphocytic gastritis was diagnosed when the number of intraepithelial lymphocytes was $30 \%$ or more of the number of epithelial cells in the areas of maximal lymphocytic concentration. ${ }^{26}$

Measurement of mucosal and foveolar thickness The mucosal and foveolar thicknesses of the body mucosa were measured on sections vertical to the mucosal surface using an image analysis system (Krypton-40, Flovel). Values were expressed as the mean of measurements along three or more different foveolae. Glandular thickness was calculated by subtracting foveolar thickness from mucosal thickness. ight $H$ pylori negative) (Table eight $H$ pylori negative) (Table $\mathrm{I}$. . The group of eight patients demonstrated crowded, tortuous, and enlarged folds in the gastric body on a barium study performed as part of a mass screening for gastric carcinoma. Subsequently, they underwent endoscopic examination and were confirmed to have inflammation and $H$ pylori colonisation of the body mucosa. The other group of 13 patients without enlarged folds underwent endoscopic examination because of complaints of dyspepsia; they were divided into two groups according to the presence or absence of $H$ pylori infection. The width of the body fold was measured on double contrast radiographs in the supine position. Body folds were considered to be enlarged when the widest fold was greater than $5 \mathrm{~mm}$ according to the previous studies and the Sydney system. ${ }^{22}{ }^{23}$ No patients had either peptic ulcer disease or gastric cancer. Hypoproteinaemia (total protein concentration $<6.5 \mathrm{~g} / \mathrm{dl}$ ) was found in two of the patients with enlarged fold gastritis $(6.3$ and $6.4 \mathrm{~g} / \mathrm{dl})$. All patients had not received any antisecretory drugs before and during this study. Informed consent was obtained from all patients.

The diagnosis of $H$ pylori infection was based on successful culture (Department of Chemotherapy, Pharmacological Research Laboratory of Fujisawa Pharmaceutical Co, Osaka, Japan) or the results of a urease test (CLOtest, Delta West), or both, using biopsy specimens from the antrum and the greater curvature of the upper portion of the gastric body. ${ }^{15}$

\section{Assessments of inflammatory infiltrates}

Biopsy specimens were fixed immediately with $4 \%$ paraformaldehyde. Thin sections of fixed tissues were stained with haematoxylin and eosin for visualisation of mononuclear and polymorphonuclear infiltration. Immunostaining for macrophage infiltration was performed with monoclonal mouse antihuman macrophage, $\mathrm{CD}^{24}$ (Dako-CD68, KP1). Infiltrations of mononuclear and polymorphonuclear cells, and macrophages were graded as follows: $0=$ none or minimal, $1=$ mild, $2=$ moderate, and $3=$ severe $^{23}$ Immunostaining for CD68 was performed using the peroxidase: antiperoxidase method. ${ }^{25}$ The anti-CD68 was used at a dilution of 1:50. The reaction was visualised using

\section{Assessment of epithelial cell proliferation}

Thin sections of $4 \%$ paraformaldehyde fixed tissues were immunostained for proliferating cells with monoclonal mouse anti-proliferating cell nuclear antigen (PCNA) ${ }^{27}$ (Dako-PCNA, $P C 10)$. Epithelial cell proliferation in the body mucosa was assessed by calculating the percentage of PCNA positive nuclei of the total nuclei in the glandular neck regions (PCNA labelling index) after counting at least 1000 total nuclei using the image analysis system. ${ }^{28}$ Immunostaining for PCNA was performed using a microwave assisted streptavidin-biotin peroxidase method. ${ }^{29}$ The anti-PCNA was used at a dilution of 1:50. The reaction was visualised using 3,3'-diaminobenzidine tetrachloride as a substrate. Negative control was used with mouse IgG instead of the antiPCNA, and no detectable staining was seen.

Determination of HGF and TGF $\alpha$ mRNA levels In five patients with enlarged fold gastritis, four $H$ pylori positive and five $H$ pylori negative patients without enlarged folds, HGF and TGF $\alpha$ mRNA levels in the body mucosa were determined by a competitive reverse transcription/polymerase chain reaction method in which rat mRNA was used as an internal standard. ${ }^{30} 31$ Total RNA was extracted from three biopsy specimens by the guanidinium thiocyanate/acid phenol methods. ${ }^{32}$ To obtain an internal standard, total RNA was extracted from rat stomach. To amplify HGF mRNA, we used two pairs of primers: the sequences were 5'-CCAATACCATTTGGAATGGA-3' for the first step 5' primer, 5'-CCATTTACAACTCGCAGTTG-3' primer. For the amplification of TGF $\alpha$ mRNA, two pairs of primers were used: the sequences were 5'-TGCCCAGATTCCCACACTCA-3' for the first step 5' primer, 5'-TTCAGGAGGGCGCTGGGCTT-3' for the first step 3' primer, 5'-ACCTGCAGGTTTTTGGTGCA-3' for the second step 5' primer and 5'-CGGCACCACTCACAGTG-3' for the second step $3^{\prime}$ primer. To amplify $28 \mathrm{~S}$ ribosomal RNA (rRNA), a pair of primers were used: the sequences were 5'-CCATGTGAACAGCAGTTGAA-3' for the 5' primer and 
5'-CCCTGCCCTTCACAAAGAAA-3' for the 3' primer. Although both human and rat cDNAs originating from HGF mRNA, TGF $\alpha$ mRNA and $28 \mathrm{~S}$ rRNA were amplified by the same primers, only the human DNA fragments from HGF mRNA, TGF $\alpha$ mRNA, and $28 S$ rRNA had the $B g l$ II, Eae I, and Eae I restriction endonuclease sites, respectively. The human and rat RNA mixtures were converted to cDNA with $R A V-2$ reverse transcriptase (Takara). Obtained cDNAs were amplified with respective primers and Thermus aquaticus DNA polymerase (Perkin-Elmer Cetus). The DNA fragments originating from $\mathrm{HGF}$ mRNA, TGF $\alpha$ mRNA, and 28S rRNA were digested with $B g l$ II (Nippon Gene), Eae I (Takara), and Eae I, respectively. Digested samples were separated into three peaks of DNA fragments using a high performance liquid chromatography column (TSK gel DEAE-NPR, 35 $\mathrm{mm} \times 4.6 \mathrm{~mm}$ internal diameter, Tosoh): two human fragments (smaller and larger) and a rat fragment. The peak height ratio of the larger human fragment to the rat fragment was used to determine the ratio of amplified DNA fragment from the human mRNA to that from the rat mRNA. As accurate quantitation of trace amounts of human total RNA obtained from biopsy specimens was difficult, the HGF or TGF $\alpha$ mRNA level was expressed as a relative HGF or TGF $\alpha$ mRNA/28S rRNA ratio.

\section{In vitro short-term culture}

HGF and IL $1 \beta$ release from the body mucosa were examined using in vitro short-term culture of biopsy specimens from the greater curvature of the upper portion of the body. ${ }^{33}$ After washing in $0.01 \mathrm{M}$ phosphate buffered saline, four specimens were cultured in $1 \mathrm{ml}$ of culture medium at $37^{\circ} \mathrm{C}$ in a $95 \%$ air and $5 \%$ $\mathrm{CO}_{2}$ humidified incubator for 24 hours. Culture medium consisted of RPMI 1640 (Research Foundation for Microbial Diseases of Osaka University) supplemented with $10 \%$ fetal bovine serum (BioWhittaker), $6 \mathrm{mg} / 1 \mathrm{van}$ comycin hydrochloride (Sigma), and $2.5 \mathrm{mg} / \mathrm{l}$ amphotericin B (Sigma). Culture supernatants were collected, centrifuged at $10000 \mathrm{~g}$, and stored at $-80^{\circ} \mathrm{C}$ until being assayed. The specimens were homogenised in $1 \mathrm{ml}$ of $0.01 \mathrm{M}$ phosphate buffered saline, and assayed for total protein concentration using the method involving bicinchoninic acid ${ }^{34}$ (BCA* Protein Assay Reagent, Pierce).

In seven patients with enlarged fold gastritis, HGF release from the body mucosa was examined in the presence and absence of 1 $\mu \mathrm{g} / \mathrm{ml}$ of recombinant human IL 1 receptor antagonist $^{35}$ (R\&D Systems) using four biopsy specimens, respectively. It had been ascertained that this IL 1 receptor antagonist inhibits HGF release in a dose dependent manner with a maximal effect at a dose of $1 \mu \mathrm{g} / \mathrm{ml}$.

\section{$H G F$ and IL $1 \beta$ assays}

HGF and IL $1 \beta$ concentrations in culture supernatants were determined using enzyme linked immunosorbent assays ${ }^{36} 37$ (HGF
'Otsuka' ELISA Kit and Human Interleukin $1 \beta$ ELISA Kit, Otsuka). The minimum detectable concentrations of HGF and IL $1 \beta$ were $10 \mathrm{pg} / \mathrm{ml}$ and $2 \mathrm{pg} / \mathrm{ml}$, respectively. The intra and inter assay coefficient of variances were less than $15 \%$ and $10 \%$, respectively. The IL $1 \beta$ assay had no cross reactivity with interleukin $1 \alpha$.

\section{Immunostaining for $\mathrm{HGF}$}

Thin sections of $4 \%$ paraformaldehyde fixed tissues were immunostained for HGF with monoclonal mouse antihuman HGF (HybT6912, Institute of Immunology Co, Tokyo, Japan). ${ }^{38}$ Immunostaining for HGF was performed by the peroxidase: antiperoxidase method. The anti-HGF was used at a dilution of 1:100. The reaction was visualised using 3,3'-diaminobenzidine tetrachloride as a substrate. Negative control was used with mouse IgG instead of the anti-HGF, and no detectable staining was seen.

\section{Treatment for $\mathrm{H}$ pylori infection}

The patients with enlarged fold gastritis (all $H$ pylori positive) received triple agent therapy consisting of bismuth subnitrate or subcarboxylate, $1 \mathrm{~g}$ thrice daily; metronidazole, $250 \mathrm{mg}$ twice daily; and tetracycline hydrochloride, $250 \mathrm{mg}$ four times daily for three weeks. ${ }^{15} 18$ At four to 23 (mean (SEM) 10.1 $(2 \cdot 8)$ ) weeks after completion of this treatment schedule, fasting serum gastrin concentrations, endoscopic examinations, and gastric secretion studies were repeated. At seven to 25 (mean (SEM) $14.0(2 \cdot 0)$ ) weeks after completion of treatment, an upper gastrointestinal barium study was repeated for reassessment of the size of the folds. Eradication of $H$ pylori was successful in all patients.

\section{Statistical analysis}

All results are expressed as mean (SEM). Statistical analysis was performed using the Kruskal-Wallis test, the Mann-Whitney test, and the Wilcoxon signed rank test. Determinations of the Pearson's correlation coefficient also were made. A p value of less than 0.05 was considered statistically significant.

\section{Results}

$\mathrm{H}$ pylori status

$H$ pylori was present in all eight patients with enlarged fold gastritis and five of 13 patients without enlarged folds (Table I). $H$ pylori was positive in both the antrum and the body except for two patients (one with enlarged fold gastritis and one without enlarged folds) who had positivity of $H$ pylori only in the body.

\section{Inflammatory infiltrates}

Histological examinations demonstrated that the inflammatory infiltrates in the body mucosa of the patients with enlarged fold 
TABLE II Inflammatory infiltrates in the body mucosa

\begin{tabular}{|c|c|c|c|}
\hline & $\begin{array}{l}\text { Mononuclear } \\
\text { infiltrates } \\
\text { (grade }\end{array}$ & $\begin{array}{l}\text { Polymorphonuclear } \\
\text { infiltrates } \\
\left.\text { (grade })^{\star}\right)\end{array}$ & $\begin{array}{l}\text { Macrophage } \\
\left.\text { (grade }{ }^{\star}\right)\end{array}$ \\
\hline \multicolumn{4}{|c|}{ Enlarged fold gastritis $(n=8)$} \\
\hline Before eradication & $1.9(0.2) \dagger$ & $1.3(0.3) \dagger$ & $2 \cdot 4(0 \cdot 3)+5$ \\
\hline After eradication & $1.0(0.0) \neq \delta \|$ & $0.0(0.0) 9 \|$ & $0.8(0 \cdot 2) \varsigma \|$ \\
\hline \multicolumn{4}{|l|}{ Non-enlarged fold } \\
\hline $\begin{array}{l}\text { H pylori }(+)(\mathrm{n}=5) \\
\text { H pylori }(-)(\mathrm{n}=8)\end{array}$ & $\begin{array}{l}1.6(0.3) \ddagger \\
0.5(0.2)\end{array}$ & $\begin{array}{l}0.8(0.2) \dagger \\
0.0(0.0)\end{array}$ & $\begin{array}{l}1.4(0.3) \\
0.9(0.1)\end{array}$ \\
\hline
\end{tabular}

All results are expressed as mean (SEM). ${ }^{\star}$ Four grades; $0=$ none or minimal, $1=$ mild,

$2=$ moderate, and $3=$ severe. $\nmid \mathrm{p}<0.01$ and $\neq \mathrm{p}<0.05 \mathrm{v}$ non-enlarged fold, $H$ pylori $(-)$. $\$ \mathrm{p}<0.05$ and $2=$ moderate, and $3=$ severe. $\nmid \mathrm{p}<0.01$ and $\neq \mathrm{p}<0.05 v$ non-enlar
$\| \mathrm{p}<0.01 v$ non-enlarged fold, $H$ pylori $(+) . \| \mathrm{p}<0.05 v$ before.

gastritis were significantly more severe than those in the $H$ pylori negative patients without enlarged folds $(p<0.01)$ (Table II). When the patients with enlarged fold gastritis were compared with the $H$ pylori positive patients without enlarged folds, macrophage infiltration in the body mucosa was significantly more extensive in the patients with enlarged fold gastritis $(\mathrm{p}<0.05)$ (Fig 1$)$. When the $H$ pylori positive patients without enlarged folds were compared with the $H$ pylori negative patients without enlarged folds, both mononuclear and polymorphonuclear infiltrates were significantly more severe in the $H$ pylori positive patients without enlarged folds $(p<0.05$ and $p<0.01$, respectively). Lymphocytic gastritis was not found in any patients.

\section{Mucosal hyperplasia and epithelial cell proliferation}

In the patients with enlarged fold gastritis, the mucosal and foveolar thicknesses of the body mucosa were significantly greater than those in both the $H$ pylori positive and negative patients without enlarged folds $(p<0.01)$ (Table III) (Fig 2). Glandular thickness, however, did not significantly differ among the three groups. The foveolar/glandular thickness ratio in the patients with enlarged fold gastritis was significantly higher than that in the $H$ pylori negative patients without enlarged folds $(p<0 \cdot 01)$. There were no significant differences in mucosal, foveolar, and glandular thickness, and the foveolar/glandular thickness ratio between the $H$ pylori positive and negative patients without enlarged folds.

PCNA labelling indices in the body mucosa that were assessable in six patients with enlarged fold gastritis, one $H$ pylori positive patient without enlarged folds, and four $H$ pylori negative patients without enlarged folds, were $20 \cdot 8(2 \cdot 7) \%, 7 \cdot 2 \%$, and $9 \cdot 0(0 \cdot 8) \%$,

TABLE III Mucosal, foveolar, glandular thicknesses, and foveolar/glandular thickness ratio of the body mucosa

\begin{tabular}{|c|c|c|c|c|}
\hline & $\begin{array}{l}\text { Mucosal } \\
\text { thickness } \\
(\mu \mathrm{m})\end{array}$ & $\begin{array}{l}\text { Foveolar } \\
\text { thickness } \\
(\mu \mathrm{m})\end{array}$ & $\begin{array}{l}\text { Glandular } \\
\text { thickness } \\
(\mu \mathrm{m})\end{array}$ & $\begin{array}{l}\text { Foveolar/glandular } \\
\text { thickness ratio }\end{array}$ \\
\hline \multicolumn{5}{|c|}{ Enlarged fold gastritis $(n=8)$} \\
\hline Before eradication & $961(55)^{\star} \dagger$ & $442(39)^{\star} \dagger$ & $519(40)$ & $0.879(0.096)^{\star}$ \\
\hline \multicolumn{3}{|l|}{ Non-enlarged fold } & $562(17)^{\star}$ & $0.530(0.026)$ ๆ \\
\hline H pylori $(+)(\mathrm{n}=5)$ & $608(51)$ & $190(17)$ & $418(62)$ & $0.538(0.153)$ \\
\hline H pylori $(-)(\mathrm{n}=8)$ & $597(30)$ & $178(11)$ & $420(25)$ & $0.432(0.034)$ \\
\hline
\end{tabular}

All results are expressed as mean (SEM). ${ }^{\star} \mathrm{p}<0.01 v$ non-enlarged fold, $H$ pylori $(-) .+\mathrm{p}<0.01 v$ non-enlarged fold, $H$ pylori $(+) . \eta \mathrm{p}<0.05 v$ before.

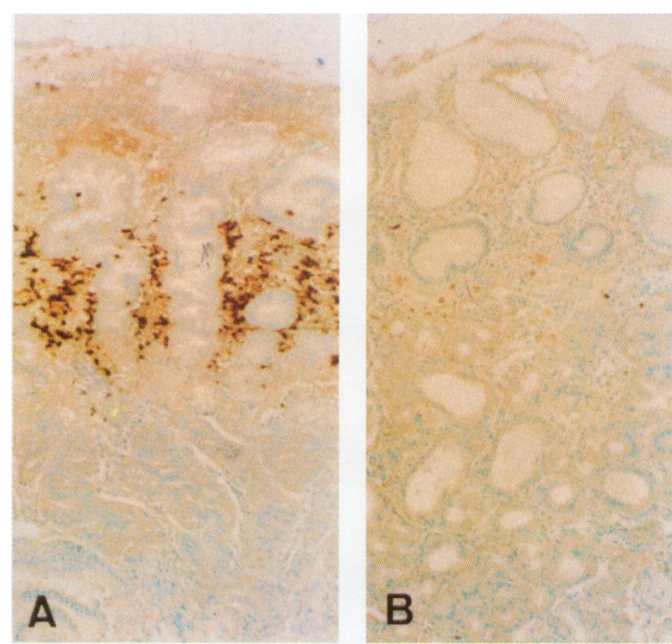

Figure 1: Immunostaining for macrophages in the body mucosa with antihuman macrophage, CD 68 before $(A)$ and after $(B)$ eradication of $\mathrm{H}$ pylori in the patients with enlarged fold gastritis. (A) Abundant $C D 68$ immunoreactivity is visible in the lamina propria (original magnification $\times 100$ ). (B) CD68 immunoreactivity is considerably decreased (original magnification $\times 100$ ). Immunoperoxidase stain; paraffin wax embedded sections, methylgreen counterstain.
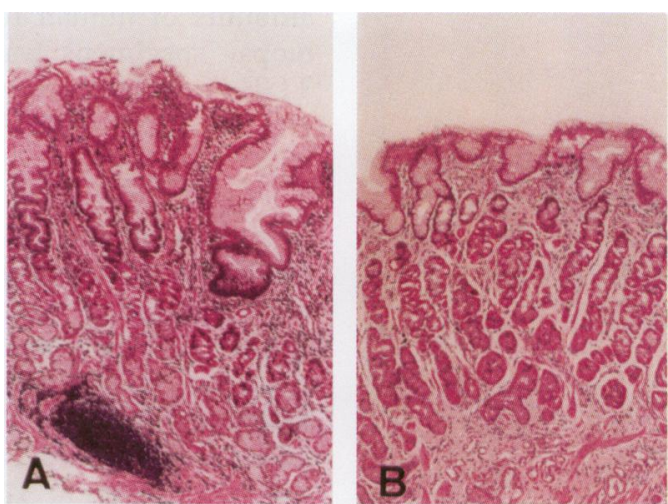

Figure 2: Haematoxylin and eosin staining of the body mucosa before $(A)$ and after $(B)$ eradication of $\mathrm{H}$ pylori in the patients with enlarged fold gastritis. $(A)$ Thickened and tortuous foveola, and severe infiltration to the lamina propria by inflammatory cells are visible (original magnification $\times 60$ ). (B) The foveolar thickness and inflammatory infiltrates have decreased (original magnification $\times 60$ ).

respectively. The PCNA labelling index in the patients with enlarged fold gastritis was higher than those in the $H$ pylori positive and negative patients without enlarged folds $(\mathrm{p}<0.05 v$ $H$ pylori negative patients).

$H G F$ and TGF $\alpha$ mRA levels

HGF mRNA levels in the body mucosa of the patients with enlarged fold gastritis were significantly higher than those in both the $H$ pylori positive and negative patients without enlarged folds $(11.46(1.44) v 3.54(0.54) v 4.38(1.05)$, $\mathrm{p}<0.05$ and $\mathrm{p}<0.01$, respectively). However, a significant difference was not found in TGF $\alpha$ mRNA levels among the patients with enlarged fold gastritis and the $H$ pylori positive and negative patients without enlarged folds $(0.49(0.11) \quad v \quad 0.47(0.06) \quad v \quad 0.50(0.13))$ (Fig 3). 

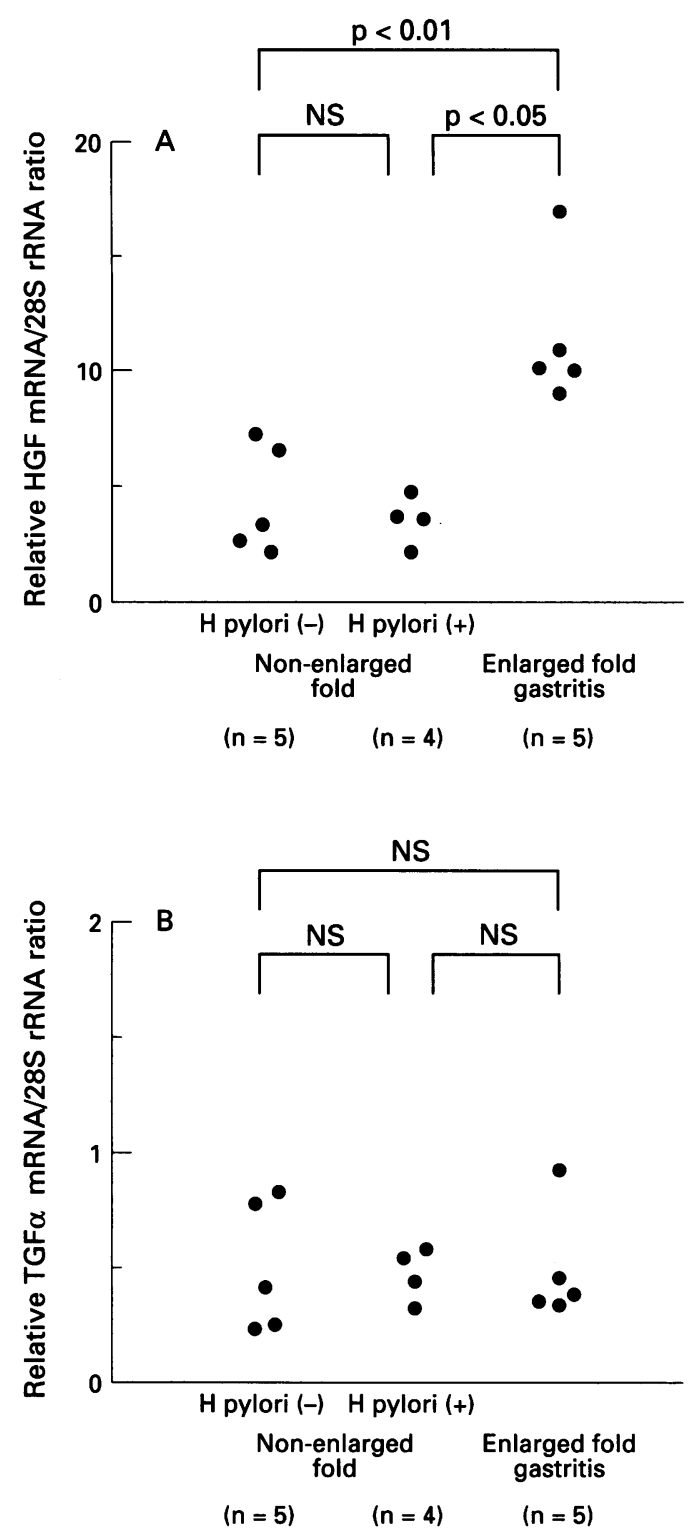

Figure 3: Hepatocyte growth factor $(H G F)(A)$ and transforming growth factor $\alpha(B) m R N A$ levels in the body mucosa of the $\mathrm{H}$ pylori negative and positive patients without enlarged folds and the patients with enlarged fold gastritis. Enlarged fold gastritis, gastritis accompanied with enlarged folds (the widest fold $>5 \mathrm{~mm}$ ). TGF $\alpha$ : transforming growth factor $\alpha, r R N A$ : ribosomal RNA, NS: not significant.

\section{$H G F$ and $I L 1 \beta$ release}

HGF release from the body mucosa in the patients with enlarged fold gastritis was much greater than that in both the $H$ pylori positive and negative patients without enlarged folds $(5.74(0.77) v 2.84(0.81) v 1.24(0.12) \mathrm{ng} 24$ hours/mg protein, $\mathrm{p}<0.05$ and $\mathrm{p}<0.01$, respectively) (Fig 4). In the patients with enlarged fold gastritis, IL $1 \beta$ release from the body mucosa also was much greater than that in both the $H$ pylori positive and negative patients without enlarged folds $(478 \cdot 1(77 \cdot 5) v$ $81.8(45.1)$ v $2.8(0.9) \mathrm{pg} 24$ hours/mg protein, p $<0.01)$. When the $H$ pylori positive patients without enlarged folds were compared with the $H$ pylori negative patients without enlarged folds, HGF and IL $1 \beta$ release both were greater in the $H$ pylori positive patients without enlarged folds $(p<0.01)$. A significant correlation was found between IL $1 \beta$ and HGF release in the body mucosa of the patients with $H$ pylori infection $(r=0.854, \mathrm{p}<0.01)$ (Fig 5).
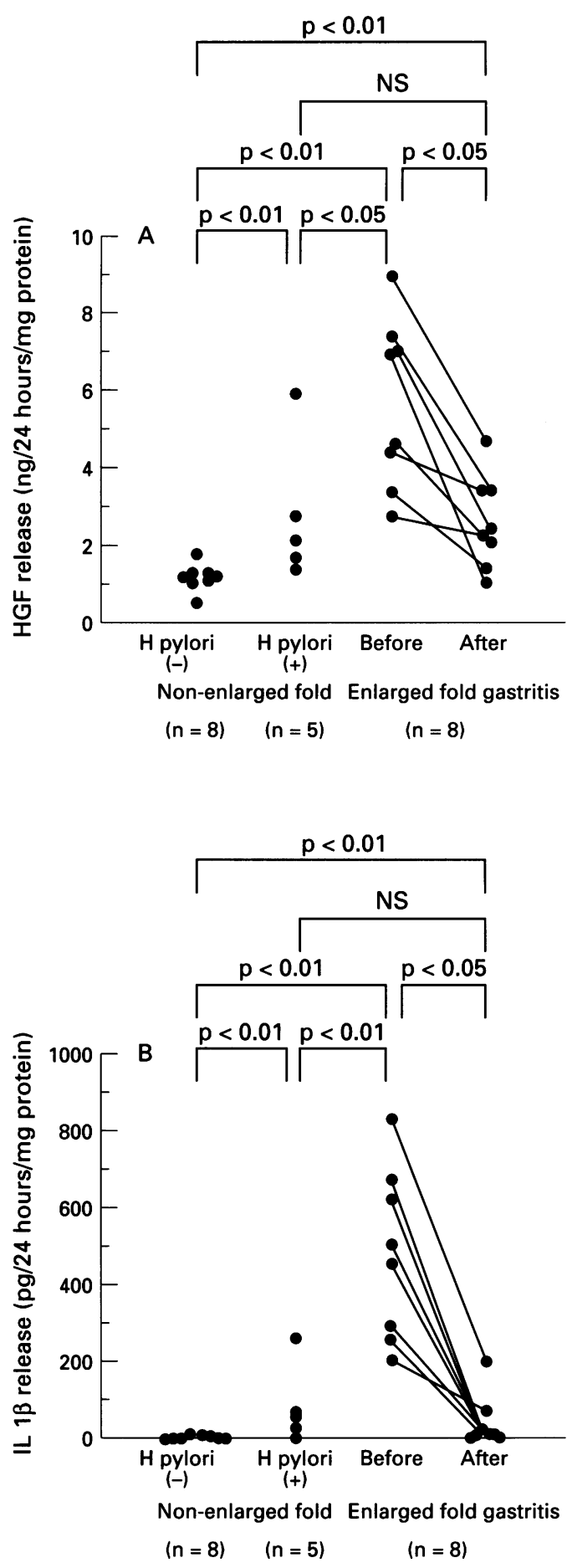

Figure 4: $H G F(A)$ and interleukin $1 \beta$ (IL 1 $\beta$ ) (B) release from the body mucosa of the $\mathrm{H}$ pylori negative and positive patients without enlarged folds, and the patients with enlarged fold gastritis before and after eradication of $\mathrm{H}$ pylori.

HGF release also was significantly correlated with foveolar thickness $(r=0.569, \mathrm{p}<0.05)$.

HGF release from the body mucosa in the presence of an IL 1 receptor antagonist was significantly less than that in the absence of this IL 1 receptor antagonist in patients with enlarged fold gastritis $(p<0.05)$ (Fig 6).

\section{Effects of eradication of $\mathrm{H}$ pylori}

After eradication of $H$ pylori in the patients with enlarged fold gastritis, the width of the body folds in the patients with enlarged fold gastritis, which had been much greater than those in 

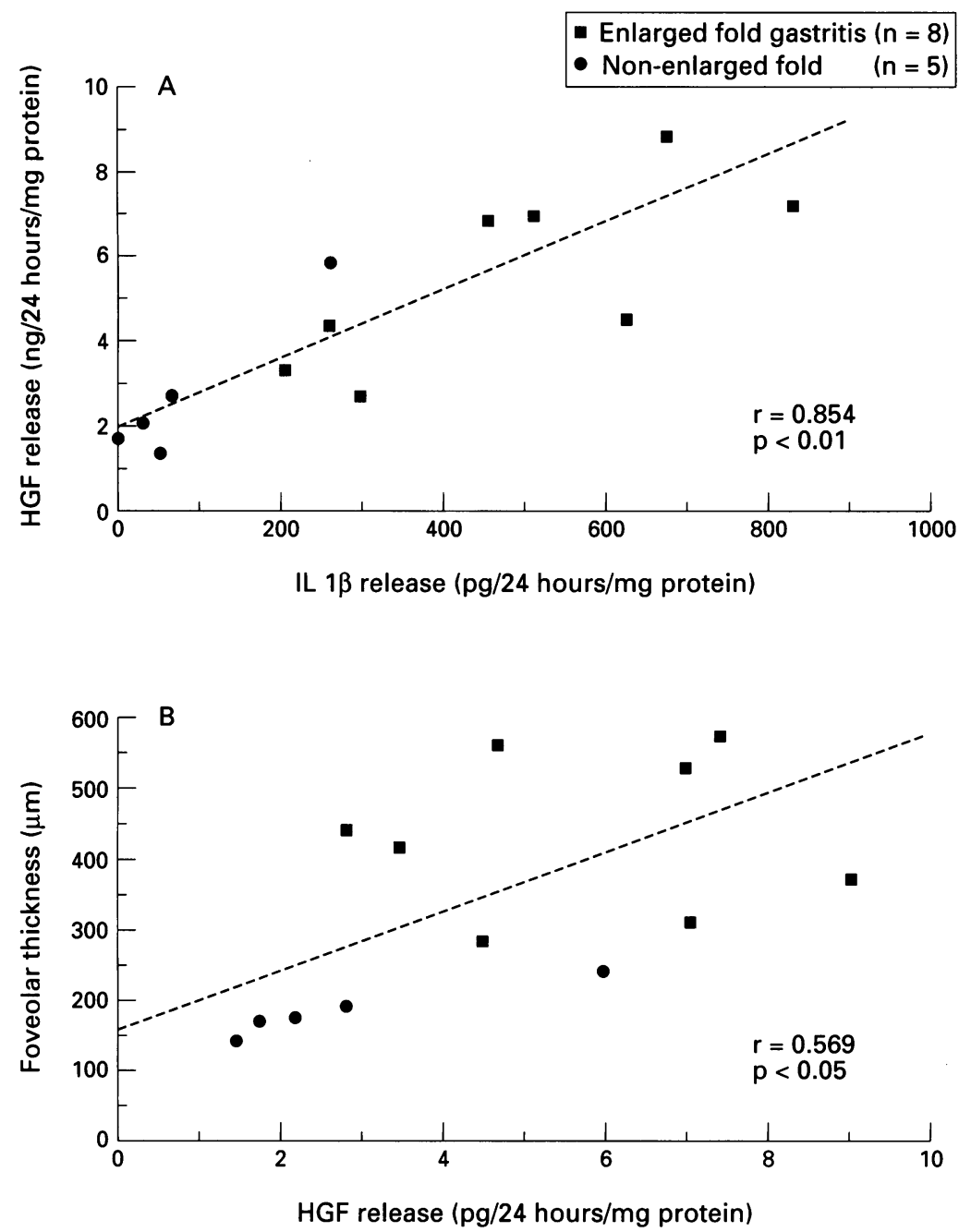

Figure 5: Relations between $I L 1 \beta$ and $H G F$ release from the body mucosa $(A)$, and between HGF release and foveolar thickness of the body mucosa (B) in the patients with $\mathrm{H}$ pylori infection. A broken line represents a regression line.

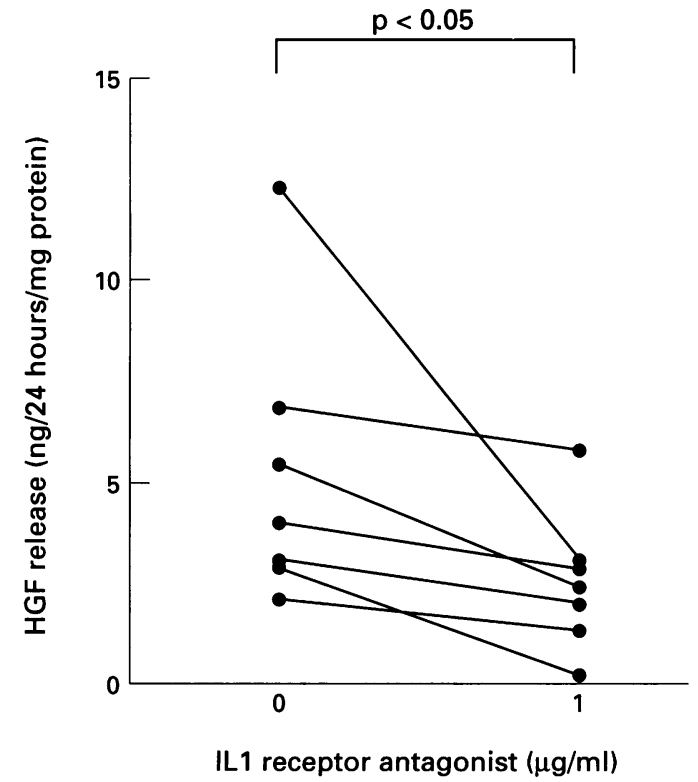

Figure 6: HGF release from the body mucosa in the absence and presence of an interleukin 1 receptor antagonist in the patients with enlarged fold gastritis.

the $H$ pylori positive and negative patients without enlarged folds (Table I), significantly decreased from $10.6(0.6) \mathrm{mm}$ to $7 \cdot 1(0.4) \mathrm{mm}$ $(p<0 \cdot 05)$. However, fold width after eradi- cation was still greater than values in both the $H$ pylori positive and negative patients without enlarged folds $(p<0 \cdot 01)$. The polymorphonuclear infiltrates in the body mucosa disappeared $(p<0.05)$ (Table II). Mononuclear and macrophage infiltrations also significantly decreased ( $p<0.05$ ) (Figs 1 and 2), but mononuclear infiltrates remained in mild degrees. Mucosal and foveolar thicknesses, and the foveolar/glandular thickness ratio of the body mucosa also significantly decreased $(p<0.05)$, but glandular thickness did not significantly change (Table III) (Fig 2). Mucosal and foveolar thicknesses after eradication were still greater than those in both the $H$ pylori positive and negative patients without enlarged folds $(p<0.01)$. Glandular thickness after eradication was greater than those in the $H$ pylori negative patients without enlarged folds $(p<0.01)$. The PCNA labelling index, which was assessable in five patients, decreased significantly from 21.4 $(3.2)$ to $12 \cdot 1 \quad(1 \cdot 8) \% \quad(\mathrm{p}<0.05)$. Significant decreases also were found in HGF $(2 \cdot 70(0.41)$ ng 24 hours/mg protein) and IL $1 \beta$ release $(42.5$ $(23 \cdot 3) \mathrm{pg} 24$ hours/mg protein) from the body mucosa $(\mathrm{p}<0 \cdot 05)($ Fig 4$)$.

\section{Immunostaining for $\mathrm{HGF}$}

In the patients with enlarged fold gastritis before treatment, HGF immunoreactivity was abundantly present in the lamina propria, and observable mainly in polymorphonuclear cells and less frequently in comparatively large sized mononuclear cells with rich intracytoplasmic vesicles, which were thought to be macrophages (Fig 7). After eradication of $\mathrm{H}$ pylori, HGF immunoreactivity was only sparsely present in the lamina propria, and observed only in the mononuclear cells. In the patients with $H$ pylori negative patients without enlarged folds, HGF immunoreactivity was observed in the small number of mononuclear cells.

\section{Discussion}

The results of this study indicate that patients with enlarged fold gastritis have extensive infiltrations of polymorphonuclear and mononuclear cells, especially macrophages, with $H$ pylori colonisation in their gastric body mucosa. This study also demonstrates that mucosal thickness, especially foveolar thickness, of the body mucosa is increased in patients with enlarged fold gastritis. The mean mucosal and foveolar thicknesses of the patients in this study were compatible with the mucosal hyperplasia and profound foveolar hyperplasia previously reported. ${ }^{339}$ These results suggest that thickening of the gastric folds in enlarged fold gastritis is due to the combination of foveolar hyperplasia and intense inflammation in the lamina propria. This study further shows that epithelial cell proliferation in the body mucosa is increased in patients with enlarged fold gastritis, suggesting that foveolar hyperplasia in enlarged fold gastritis is due to increased epithelial cell proliferation.

Enlarged folds and foveolar hyperplasia in the inflamed body mucosa have been reported 


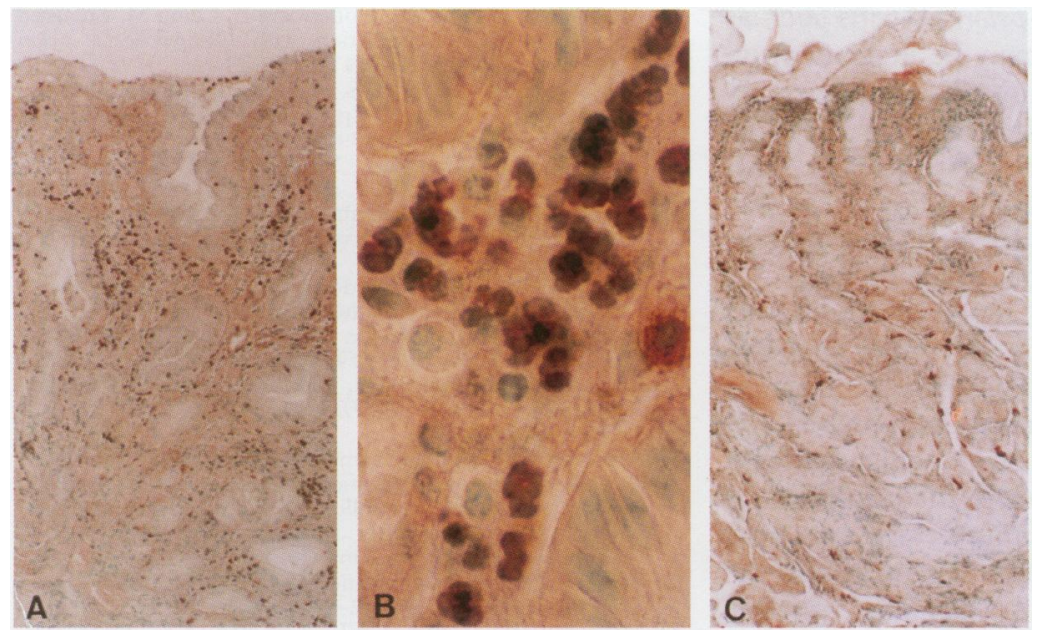

Figure 7: Immunostaining for $H G F$ before $(A, B)$ and after $(C)$ eradication of $\mathrm{H}$ pylori in the patients with enlarged fold gastritis. (A) Abundant HGF immunoreactivity is visible in the lamina propria (original magnification $\times 150$ ). (B) HGF immunoreactivity is mainly observable in polymorphonuclear cells (original magnification $\times 1500$ ). (C) $H G F$ immunoreactivity is now only sparsely present in the lamina propria (original magnification $\times 150)$. Immunoperoxidase stain with a monoclonal anti-HGF; paraffin wax embedded sections, methylgreen counterstain.

in patients with hypertrophic lymphocytic gastritis, which is a rare type of gastritis characterised by a considerable increase in intraepithelial lymphocytes $(30 \%$ or more of the number of epithelial cells). ${ }^{326}{ }^{40}$ Enlarged fold gastritis in this study resembled hypertrophic lymphocytic gastritis with the presence of a comparatively severe grade of chronic active inflammation and foveolar hyperplasia. However, intraepithelial infiltration of polymorphonuclear cells, rather than lymphocytes, was found in this study, and no cases were compatible with lymphocytic gastritis. Hypertrophic lymphocytic gastritis may be regarded as a rare type of enlarged fold gastritis. Wolfsen et $a l^{3}$ have reported that patients previously diagnosed with Ménétrier's disease actually represent at least two diseases: (1) hypertrophic lymphocytic gastritis and (2) massive foveolar hyperplasia and minimal inflammation (classic Ménétrier's disease). They have shown that medians (range) of mucosal thickness and foveola/gland ratio in patients with classic Ménétrier's disease are 5.5 $(2 \cdot 5-12 \cdot 5) \mathrm{mm}$ and $9 \cdot 5(3-15)$, respectively. In our study, those in the patients with enlarged fold gastritis were $0.960(0.706-1.214) \mathrm{mm}$ and $0.818(0.563-1.234)$, respectively. Therefore, enlarged fold gastritis in our study is considered to be distinguishable from classic Ménétrier's disease. Our finding that two patients with enlarged fold gastritis had hypoproteinaemia may suggest that enlarged fold gastritis is one of the causes of protein loosing gastropathy as well as Ménétrier's disease and lymphocytic gastritis. ${ }^{40}$

This study also shows that IL $1 \beta$ and HGF release from the body mucosa is increased in patients with enlarged fold gastritis. In addition, this study shows that macrophage infiltration in the body mucosa is significantly increased in patients with enlarged fold gastritis. IL $1 \beta$ is known to be produced mainly by activated monocytes/macrophages, and has been reported to induce $\mathrm{HGF}$ release in human fibroblasts in vitro. ${ }^{12-14}$ This study further shows that HGF release significantly correlated with IL $1 \beta$ release in patients with enlarged fold gastritis and $H$ pylori positive patients without enlarged folds, and is significantly decreased in the presence of an IL 1 receptor antagonist in patients with enlarged fold gastritis. These findings strongly suggest that HGF is induced by IL $1 \beta$ in enlarged fold gastritis. These results also suggest that infiltration and activation of macrophages result in raised IL $1 \beta$ and HGF release in this condition. Furthermore, the results of this study suggest that HGF producing cells are mainly polymorphonuclear leucocytes and less often macrophages in the body mucosa of patients with enlarged fold gastritis. This is consistent with reports stating that HGF immunoreactivity is present in granulocytes in the bone marrow, spleen, and diseased liver, as well as in macrophages in the lymph nodes, respiratory tract, and liver (Kupffer cells).$^{8-11}$

TGF $\alpha$ and HGF are well known, potent growth factors, which induce a mitogenic response in gastric epithelial cells. ${ }^{45}$ It also has been shown that severe foveolar hyperplasia occurs in transgenic mice overexpressing TGF $\alpha$ in the stomach, suggesting that TGF $\alpha$ plays a part in the pathogenesis of Ménétrier's disease. ${ }^{6} 7$ There have been no reports about the association between HGF and the hyperplastic state of gastric mucosa. In this study, HGF mRNA levels, but not TGF $\alpha$ mRNA levels, in the body mucosa were increased in the patients with enlarged fold gastritis. This study also showed that HGF release from the body mucosa was significantly increased in the patients with enlarged fold gastritis. Moreover, foveolar thickness of the body mucosa significantly correlated with HGF release in patients with enlarged fold gastritis and $H$ pylori positive patients without enlarged folds. These results suggest that HGF is possibly involved in foveolar hyperplasia through stimulating epithelial cell proliferation in enlarged fold gastritis. Furthermore, this study suggests that HGF may be induced by IL $1 \beta$ in enlarged fold gastritis. Recently, it has been shown that intestinal epithelial cells (IEC-18 and Caco-2) express the type I IL 1 receptor and that IL $1 \beta$ increases proliferation of Caco-2 cells. $^{41}{ }^{42}$ However, it has not been shown whether IL $1 \beta$ increases epithelial cell proliferation in the stomach directly. IL $1 \beta$ may participate in gastric epithelial cell proliferation, at least through stimulating HGF release.

This study further demonstrates that eradication of $H$ pylori in patients with enlarged fold gastritis decreases inflammatory infiltrates, including macrophages, IL $1 \beta$, and HGF release, with concomitant improvement in epithelial cell hyperproliferation, foveolar hyperplasia, and fold enlargement. However, foveolar thickness and fold width after eradication were still greater than those values in $H$ pylori positive and negative patients without enlarged folds. These results suggest that $H$ pylori infection causes infiltration and activation of macrophages, leading to increased IL $1 \beta$ and HGF release in enlarged fold gastritis. It is unclear why macrophage infiltration was increased, especially in a 
subset of patients with $H$ pylori gastritis such as those in this study. This may be dependent on the strain of $H$ pylori or immunological reactivity of the host. Decreased, but still raised, HGF release after eradication, despite the disappearance of polymorphonuclear cells, may reflect $\mathrm{HGF}$ production by activated macrophages that remained in the lamina propria.

Previously, we have reported that acid secretion is decreased in $H$ pylori positive patients with enlarged fold gastritis. ${ }^{18}$ Inhibition of acid secretion and increase in epithelial cell proliferation in patients with enlarged fold gastritis seem advantageous to the host because of reducing the mucosal injury caused by acid and pepsin, and promoting mucosal regeneration. However, it remains unclear whether the raised gastric $\mathrm{pH}$ may be for or against $H$ pylori. On the other hand, chronic inflammation, hypochlorhydria, and longstanding epithelial cell hyperproliferation and hyperplastic state may be favourable to gastric carcinogenesis because of an increase in inflammatory mutagens, the intragastric formation of $N$-nitroso compounds, and the chance of mutation. Thus, further study is needed to clarify whether or not the risk of gastric carcinoma is increased in enlarged fold gastritis, and eradication of $H$ pylori reduces the risk.

1 Rohrmann CA Jr, Seaman WB. Nonneoplastic lesions of the stomach. In: Stamathis G, ed. Alimentary tract radiology. St Louis: Mosby, 1989: 551-93.

2 Komorowski RA, Caya JG. Hyperplastic gastropathy: clinicopathologic correlation. Am f Surg Pathol 1991; 15: 577-85.

3 Wolfsen HC, Carpenter HA, Talley NJ. Menetrier's disease: a form of hypertrophic gastropathy or gastritis? Gastroenterology 1993; 104: 1310-9.

4 Rutten MJ, Dempsey PJ, Solomon TE, Coffey RJ Jr. TGF-a is a potent mitogen for primary cultures of guinea pig is a potent mitogen for primary cultures of guinea pig
gastric mucous epithelial cells. Am f Physiol 1993; 265: G361-9.

5 Takahashi M, Ota S, Shimada T, Hamada E, Kawabe T, Okudaira $\mathrm{T}$, et al. Hepatocyte growth factor is the mos potent endogenous stimulant of rabbit gastric epithelia cell proliferation and migration in primary culture. $\mathfrak{f} \mathrm{Clin}$ Invest 1995; 95: 1994-2003.

6 Dempsey PJ, Goldenring JR, Soroka CJ, Modlin IM McClure RW, Lind CD, et al. Possible role of transforming growth factor $\alpha$ in the pathogenesis of Ménétrier's disease: supportive evidence from humans and transgenic mice. Gastroenterology 1992; 103: 1950-63.

7 Takagi H, Jhappan C, Sharp R, Merlino G. Hypertrophic gastropathy resembling Menetrier's disease in transgenic gastropathy resembling Menetrier's disease in transgenic mice overexpressing transforming growth

8 Gherardi E, Sharpe M, Lane K, Sirulnik A, Stoker M. Hepatocyte growth factor/scatter factor (HGF/SF), the c-met receptor and the behaviour of epithelial cells. In: Jones G, Wigley C, Warn R, eds. Symp Soc Exp Biol XLVII Cell behaviour: adhesion and motility. Cambridge: The Company of Biologists Limited, 1993: 163-81.

9 Wolf HK, Zarnegar R, Michalopoulos GK. Localization of hepatocyte growth factor in human and rat tissues: an immunohistochemical study. Hepatology 1991; 14: 488-94.

10 Sakaguchi H, Seki S, Tsubouchi H, Daikuhara Y, Niitani $Y$, Kobayashi $K$. Ultrastructural location of human hepatocyte growth factor in human liver. human hepatocyte growth

11 Yoshinaga $Y$, Matsuno $Y$, Fujita $S$, Nakamura $T$ Kikuchi M, Shimosato Y, et al. Immunohistochemical detection of hepatocyte growth factor/scatter factor in human cancerous and inflammatory lesions of various organs. $7 p n \mathcal{F}$ Cancer Res 1993; 84: 1150-8.

12 Matsumoto K, Okazaki $\mathrm{H}$, Nakamura T. Up-regulation of hepatocyte growth factor gene expression by interleukin-1 in human skin fibroblasts. Biochem Biophys Res Commu 1992; 188: 235-43.

13 Tamura $M$, Arakaki N, Tsubouchi $H$, Takada $H$ Daikuhara Y. Enhancement of human hepatocyte growt factor production by interleukin- $1 \alpha$ and $-1 \beta$ and tumo necrosis factor- $\alpha$ by fibroblasts in culture. 7 Biol Chem 1993; 268: 8140-5.

14 Dinarello CA. Interleukin-1 and interleukin-1 antagonism. Blood 1991; 77: 1627-52.

15 Rathbone BJ, Heatley RV, eds. Helicobacter pylori and gastroduodenal disease. 2nd ed. London: Blackwell Scientific, 1992.
16 Morrison S, Dahms BB, Hoffenberg E, Czinn SJ. Enlarged gastric folds in association with Campylobacter pylor gastritis. Radiology 1989; 171: 819-21.

17 Stolte $\mathrm{M}$, Bätz $\mathrm{CH}$, Eidt S. Giant fold gastritis: a special form of Helicobacter pylori associated gastritis. Z Gastroenterol 1993; 31: 289-93.

18 Yasunaga Y, Shinomura Y, Kanayama S, Yabu M, Nakanishi T, Miyazaki Y, et al. Improved fold width and increased acid secretion after eradication of the organism in Helocobacter pylori associated enlarged fold gastritis. Gut in Helocobacter pylo

19 Stolte M, Bätz CH, Bayerdörffer E, Eidt S. Helicobacter pylori eradication in the treatment and differential diagnosis of giant folds in the corpus and fundus of the stomach. $Z$ Gastroenterol 1995; 33: 198-201.

20 Bayerdörffer E, Ritter MM, Hatz R, Brooks W, Stolte M Ménétrier's disease and Helicobacter pylori. N Engl f Med 1993; 329: 60 .

21 Avunduk C, Navab F, Hampf F, Coughlin B. Prevalence of Helicobacter pylori infection in patients with large gastric folds: evaluation and follow-up with endoscopic ultrasound before and after antimicrobial therapy. $\mathrm{Am} f$ Gastroenterol 1995; 90: 1969-73.

22 Press AJ. Practical significance of gastric rugal folds. $A m \mathcal{F}$ Roentgenol 1975; 125: 172-83.

23 Misiewicz JJ, Tytgat GNJ, Goodwin CS, Price AB Sipponen S, Strickland RG, et al. The Sydney system: a new classification of gastritis. Working party reports of the world congresses of gastroenterology; 1990 August 26-31 Sydney. Melbourne: Blackwell Scientific, 1990: 1-10.

24 Pulford KAF, Rigney EM, Micklem KJ, Jones M Stross WP, Gatter KC, et al. KP1: a new monoclonal antibody that detects a monocyte/macrophage associated antigen in routinely processed tissue sections. $\mathcal{f}$ Clin Pathol 1989; 42: 414-21.

25 Mason DY, Cordell JL, Abdulaziz Z, Naiem M, Bordenave G. Preparation of peroxidase: antiperoxidase (PAP) complexes for immunohistological labeling of monoclonal antibodies. $¥$ Histochem Cytochem 1982; 30: 1114-22.

26 Haot J, Hamichi L, Wallez L, Mainguet P. Lymphocytic gastritis: a newly described entity: a retrospective endoscopic and histological study. Gut 1988; 29: 1258-64.

27 Waseem NH, Lane DP. Monoclonal antibody analysis of the proliferating nuclear antigen (PCNA). Structural conversation and the detection of a nucleolar form. $\mathcal{f} \mathrm{Cell}$ Sci 1990; 96: 121-9.

28 Fraser AG, Sim R, Sankey EA, Dhillon AP, Pounder RE. Effect of eradication of Helicobacter pylori on gastric epithelial cell proliferation. Aliment Pharmacol Ther 1994; 8: $167-73$.

29 Guesdon J-L, Thérèse T, Avrameas $S$. The use of avidinbiotin interaction in immunoenzymatic techniques. f Histochem Cytochem 1979; 27: 1131-9.

30 Kondo S, Imamura I, Shinomura Y, Matsuzawa Y, Fukui $H$. Determination of histidine decarboxylase mRNA in various rat tissues by the polymerase chain mRNA in various rat tissues by the
reaction. Inflamm Res 1995; 44: 111-5.

31 Kondo S, Shinomura Y, Kanayama S, Higashimoto Y, Kiyohara T, Yasunaga Y, et al. Helicobacter pylori increases gene expression of hepatocyte growth factor in human gastric mucosa. Biochem Biophys Res Commun 1995; 210: $960-5$.

32 Chomczynski P, Sacchi N. Single-step method of RNA isolation by acid guanidinium thiocyanate-phenolchloroform extraction. Anal Biochem 1987; 162: 156-9.

33 Crabtree JE, Shallcross TM, Heatley RV, Wyatt JI. Mucosal tumour necrosis factor $\alpha$ and interleukin-6 in patients with Helicobacter pylori associated gastritis. Gut 1991; 32 1473-7.

34 Sorensen $\mathrm{K}$, Brodbeck U. Assessment of coating-efficiency in ELISA plates by direct protein determination. in ELISA plates by direct protein

35 Robert A, Olafsson AS, Lancaster C, Zhang W. Interleukin-1 is cytoprotective, antisecretory, stimulates $\mathrm{PGE}_{2}$ synthesis by the stomach, and retards gastric emptying. Life Sci 1991; 48: 123-34.

36 Tsubouchi $H$, Niitani $Y$, Hirono $S$, Nakayama $H$, Gohda E, Arakaki N, et al. Levels of the human hepatocyte growth factor in serum of patients with various liver diseases determined by an enzyme-linked immunosorbent assay. Hepatology 1991; 13: 1-5.

37 Tanaka K, Ishikawa E, Ohmoto Y, Hirai Y. Sandwich enzyme immunoassay for human interleukin-1 $\beta$ (hIL-1 $\beta$ ) in urine. Clin Chim Acta 1987; 166: 237-46.

38 Yamada A, Matsumoto K, Iwanari H, Sekiguchi $\mathrm{K}$, Kawata S, Matsuzawa Y, et al. Rapid and sensitive Kawata S, Matsuzawa Y, et al. Rapid and sensitive HGF in rat and human tissues. Biomed Res 1995; 16: 105-14.

39 Karttunen $T$, Niemelä $S$, Lehtola J, Heikkilä J, Mäentausta $\mathrm{O}$, Räsänen $\mathrm{O}$. Campylobacter-like organisms and gastritis: histopathology, bile reflux, and gastric fluid composition. Scand $\mathcal{F}$ Gastroenterol 1987; 22: 478-86.

40 Wolber RA, Owen DA, Anderson FH, Freeman HJ Lymphocytic gastritis and giant gastric folds associated with gastrointestinal protein loss. Mod Pathol 1991; 4: with 5

41 Varilek GW, Neil GA, Bishop WP. Caco-2 cells express type I interleukin-1 receptors: ligand binding enhances proliferation. Am F Physiol 1994; 267: G1 101-7.

42 Sutherland DB, Varilek GW, Neil GA. Identification and characterization of the rat intestinal epithelial cell (IEC-18) interleukin-1 receptor. Am f Physiol 1994; 266 C1198-203. 